\title{
Effects of light-emitting diode supplementary lighting on the winter growth of greenhouse plants in the Yangtze River Delta of China
}

\author{
Xue Li', Wei Lu', Guyue Hu${ }^{1}$, Xiao Chan Wang ${ }^{1,2^{*}}$, Yu Zhang ${ }^{1,2}$, Guo Xiang Sun ${ }^{1,2}$ and Zhichao Fang ${ }^{1}$
}

\begin{abstract}
Background: The winter in the Yangtze River Delta area of China involves more than 1 month of continuous low temperature and poor light (CLTL) weather conditions, which impacts horticultural production in an unheated greenhouse; however, few greenhouses in this area are currently equipped with a heating device. The low-cost and long-living light-emitting diode (LED) was used as an artificial light source to explore the effects of supplementary lighting during the dark period in CLTL winter on the vegetative characteristics, early yield, and physiology of flowering for pepper plants grown in a greenhouse without heating. Two LED lighting sets were employed with different

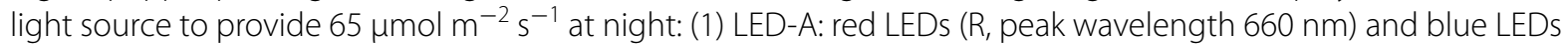
( $B$, peak wavelength $460 \mathrm{~nm}$ ) with an R:B ratio of 6:3; and (2) LED-B: R and B LEDs at an R:B ratio of 8:1. Plants growth parameters and chlorophyll fluorescence characteristics were compared between lighting treatments and the control group.
\end{abstract}

Results: Plants'yield and photosynthesis ability were improved by LED-A. Pepper grown under the LED-A1 strategy showed a $303.3 \%$ greater fresh weight of fruits and a $501.3 \%$ greater dry mass compared with the control group. Plant leaves under LED-A1 showed maximum efficiency of the light quantum yield of PSII, electron transfer rate, and the proportion of the open fraction of PSII centers, with values $113.70,114.34$, and $211.65 \%$ higher than those of the control group, respectively, and showed the lowest rate constant of thermal energy dissipation of all groups. LED-B was beneficial to the plant height and stems diameter of the pepper plants more than LED-A.

Conclusions: These results can serve as a guide for environment control and for realizing low energy consumption for products grown in a greenhouse in the winter in Southern China.

Keywords: LED, Supplementary lighting, Greenhouse, Winter, Pepper

\section{Background}

Light and temperature are the most important environmental factors affecting plant survival, dry mass distribution, and crop yield (Janda et al. 2014; Zoratti et al. 2014). Light is the direct energy source for plant photosynthesis to determine the distribution of organic materials, the morphogenesis of plant and subsequent yield (Blom and

\footnotetext{
*Correspondence: wangxiaochan@njau.edu.cn

${ }^{1}$ College of Engineering, Nanjing Agricultural University, Nanjing, Jiangsu, People's Republic of China

Full list of author information is available at the end of the article
}

Ingratta 1984; Fan et al. 2008). The temperature state can affect the activity of enzymes in plant cells to exert physiological changes (Chen and Tang 2013). Because of this close relationship between temperature and physiological reactions, temperature and lighting cues provide vital information for plants to assure optimal development (Franklin et al. 2014). Under the condition of light with a low red/far-red (R/FR) ratio and a comfortable temperature, the plant leaf area and dry mass are reduced (Patel et al. 2013); however, at lower temperatures, lighting with a low $\mathrm{R} / \mathrm{FR}$ ratio can significantly promote 
the plant-soluble sugar content and the expression of C-repeat-binding factor, a regulator of cold-acclimation genes (Franklin and Whitelam 2007). Furthermore, Marcelis (1993a, b) found that plant fruits dry mass were improved with increasing irradiance and decreasing temperature, demonstrating that when plants are in a relatively low temperature environment (or suboptimal temperature), adjusting the lighting condition exerts positive effects on plant production.

A light-emitting diode (LED) can emit the monochromatic light required for plant growth. The combination of red LEDs with blue LEDs can form a spectral absorption peak suitable for plant photosynthesis and morphogenesis with an 80-90 \% light energy utilization rate and a remarkable energy-saving effect (Yang. 2008). Some reports have indicated that the use of a single red or blue LED light source or their combination could improve the efficiency of photosynthesis to promote plant production and regulate morphogenesis (Barta et al. 1992; Fang and Jao 1996; Nhut et al. 2003; Ding et al. 2005; Xiao et al. 2013; Shen et al. 2014).

In the Yangtze River Delta region of southern China, the low temperature and poor light (CLTL) environment always lasts for more than 1 month in winter (Wu 2011). Moreover, greenhouses in this area are scarcely heated owing to the high energy consumption and costs. Consequently, this suboptimal weather in southern China is quite detrimental to plant growth and production. Most of the research conducted in this area has focused on seedling growth in response to CLTL conditions or has examined the influence of only a single factor on plant growth in order to select plants that are resistant to the harsh temperature conditions (Wang et al. 2001; Ren et al. 2002; $\mathrm{Hu}$ and $\mathrm{Yu}$ 2003). Little studies have been conducted to study how to improve the production of flowering plants grown in greenhouse under the CLTL conditions. Thus, the aim of this study was to evaluate the effects of LED supplementation on flowering plants grown in a greenhouse without heating equipment during the dark period in winter. These results should serve as a guide for environmental control and for achieving low energy consumption with high productivity in plants grown in greenhouses in the winter in southern China.

\section{Methods}

\section{Plant material and experimental design}

Experiments were conducted from December 2014 to January 2015 in a greenhouse located in the College of Engineering in Nanjing Agricultural University (Nanjing, Jiangsu Province, China, $118^{\circ} 46^{\prime} \mathrm{N}, 32^{\circ} 03^{\prime} \mathrm{E}$ ), which is characterized by a sub-tropical monsoon climate. The greenhouse is equipped with internal and external shading, skylights, a drip irrigation system, and a spray system, which are all computer-controlled. The Eco-Watch ecological environment monitoring system (Dynamax, USA) was used to monitor the micro-environmental parameters inside the greenhouse. Pepper (Capsicum frutescens L., Sujiao No. 5) was chosen as the experimental material. The seed of pepper were sown in nutrient soil (Galaku Pty Ltd., Australia) on September 10, 2014 and transplanted into plots after the fourth true leaf was fully mature. The medium was a coconut shell (Galaku Pty, Ltd.). The Yamazaki nutrient (Table 1) solution was used to supply nutrients for pepper growth. Chlorophyll fluorescence parameters were measured with the MiniPam II system (Walz, Germany), quantum photon density and light homogeneity were tested by a PAR sensor equipped by Mini-Pam II.

The LED lighting sets were established for each plant individually. Each light set consisted of 144 red ( $R$, peak wavelength $660 \mathrm{~nm}$ ) or blue (B, peak wavelength $460 \mathrm{~nm}$ ) LEDs with ultra-high brightness at an $R: B$ ratio of $6: 3$ (LED-A group) or 8:1 (LED-B group) (Hogewoning et al. 2010). The lighting area was $555 \times 22.8 \mathrm{~mm}$. The plant photosynthetic quantum flux density, measured $15 \mathrm{~cm}$ above the plants, was $65 \mu \mathrm{mol} \mathrm{m}{ }^{-2} \mathrm{~s}^{-1}$.

Plants in anthesis with similar growth trends were chosen for the experimental treatment. Supplementary lighting began on December 1, 2014 and finished on January 15,2015 . The humidity arranged from 60 to $70 \%$. Temperature was the environment temperature as well as the light. The experiment included seven treatments: six experimental groups and the control group, with six plants in per treatment. The control group was plants grown without light supplementation at night. The supplementary lighting duration and light source for each treatment are given in Table 2.

\section{Parameter measurements}

The greenhouse environmental parameters were collected by the Eco-Watch system at 15-min intervals. All

Table 1 Elements composition of Yamazaki nutrient in $1 \mathrm{~L}$ deionized water

\begin{tabular}{ll}
\hline Elements composition & Dosage $\left(\mathbf{m g ~ L}^{\mathbf{- 1}}\right)$ \\
\hline $\mathrm{Ca}\left(\mathrm{NO}_{3}\right)_{2} \cdot 4 \mathrm{H}_{2} \mathrm{O}$ & 354 \\
$\mathrm{KNO}_{3}$ & 607 \\
$\mathrm{NH}_{4} \mathrm{H}_{2} \mathrm{PO}_{4}$ & 96 \\
$\mathrm{MgSO}_{4} \cdot 7 \mathrm{H}_{2} \mathrm{O}$ & 185 \\
$\mathrm{Na}_{2} \mathrm{Fe}-\mathrm{EDTA}$ & 25 \\
$\mathrm{H}_{3} \mathrm{BO}_{3}$ & 2.13 \\
$\mathrm{MnSO}_{4} \cdot 4 \mathrm{H}_{2} \mathrm{O}$ & 2.86 \\
$\mathrm{ZnSO}_{4} \cdot 7 \mathrm{H}_{2} \mathrm{O}$ & 0.22 \\
$\mathrm{CuSO}_{4} \cdot 5 \mathrm{H}_{2} \mathrm{O}$ & 0.08 \\
$\left(\mathrm{NH}_{4}\right)_{6} \mathrm{MO}_{7} \mathrm{O}_{2} \cdot 4 \mathrm{H}_{2} \mathrm{O}$ & 0.02 \\
\hline
\end{tabular}


Table 2 The light quality and light supplementation arrangement

\begin{tabular}{llll}
\hline Light source & R/B ratio & Lighting duration & Serial number \\
\hline LED-A & $6: 3$ & 18:00-00:00 (6 h) & LED-A1 \\
& $6: 3$ & $18: 00-22: 00(4 \mathrm{~h})$ & LED-A2 \\
& $6: 3$ & $18: 00-20: 00(2 \mathrm{~h})$ & LED-A3 \\
LED-B & $8: 1$ & $18: 00-00: 00(6 \mathrm{~h})$ & LED-B1 \\
& $8: 1$ & $18: 00-22: 00(4 \mathrm{~h})$ & LED-B2 \\
& $8: 1$ & $18: 00-20: 00(2 \mathrm{~h})$ & LED-B3 \\
- & - & - & Control group \\
\hline
\end{tabular}

pepper parameters were measured after 2 weeks of light supplementation at night period. The chlorophyll fluorescence parameters of the pepper plants were tested every 7 days, with healthy canopy leaves chosen for measurement, ensuring that each measure was taken at the same location as much as possible. The chlorophyll fluorescence parameters would be measured for 5 weeks in all. The actinic light intensity was four and the SATPlus intensity was 10 , the duration of induction curve was $20 \mathrm{~s}$ with the length of 12 . The measuring time was from 17:00-21:00 after 25 min of dark adaptation for the leaves, and three leaves were tested of each plant with the averages used for statistical analysis. Three plants were randomly tested in each treatment. At the end of the experiment, the following vegetative characteristics of the plants were measured: plant height, stem diameter, and plant canopy width. The dry mass of the roots, stems, leaves, and fruits were also recorded.

\section{Statistical analysis}

Excel 2010 (Chinese version) and Origin 7.5 (Chinese version) were used for data processing and graph generation. Analysis of variance (ANOVA) was used to evaluate statistical significance among groups, and the Duncan method was used for multiple comparisons evaluated at $\mathrm{p}<0.05$ or $\mathrm{p}<0.01$ with SPSS 17.0 (Chinese version).

\section{Results}

\section{Environmental parameters in the greenhouse} during winter

Figure 1 showed the temperature and solar radiation fluctuations during daytime hours in the greenhouse. The daily minimum temperature was $7.67{ }^{\circ} \mathrm{C}$, the average temperature was $15.8{ }^{\circ} \mathrm{C}$, and the highest temperature was $22.18{ }^{\circ} \mathrm{C}$. With respect to solar radiation, the minimum value was $5.35 \mathrm{~W} \mathrm{~m}^{-2}$, the average value was $101.5 \mathrm{~W} \mathrm{~m}^{-2}$, and the maximum value was $178.86 \mathrm{~W} \mathrm{~m}^{-2}$, indicating that the peppers grown in the greenhouse were in a CLTL environment.

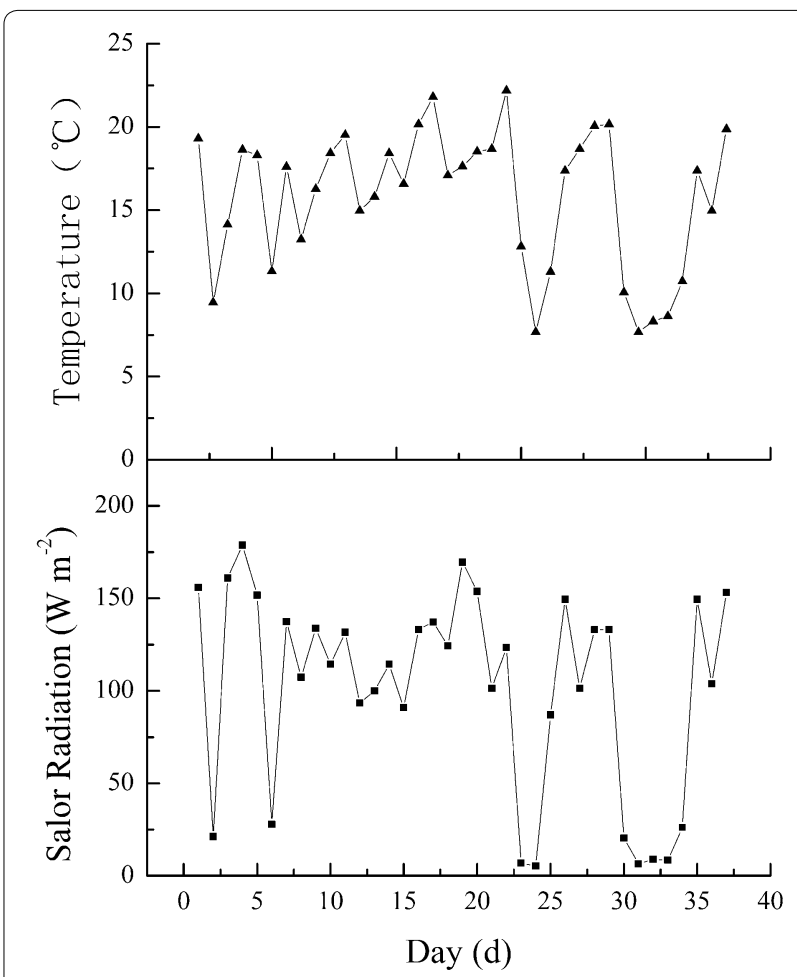

Fig. 1 Daily microclimate conditions (air temperature and solar radiation) inside the greenhouse. The data were the average of temperature and solar radiation from 6:00 to 17:00

Plant growth and development in cltl with supplementary led lighting during dark periods in winter Impacts of LED supplementary lighting on plant vegetative characteristics during the dark period

When the lighting was applied for $2 \mathrm{~h}$ during the dark period, plants grown under the LED-A treatment showed the highest plant height, which was $13.94 \%$ higher than that of the control group, representing a significant difference $(\mathrm{p}<0.05$; Fig. $2 \mathrm{a})$. The stem diameter under the LED-B treatment was significantly higher than that of the control with an increase of $5.56 \%$ (p < 0.05; Fig. 2b). No significant difference in plant canopy width or plant dry mass was observed among the groups.

When the LED lighting was applied for $4 \mathrm{~h}$, the plants grown under the LED-B treatment showed the highest plant height and stem diameter, which were 20.44 and $20.83 \%$, respectively, greater than those of the control group (Fig. 2a, b). Plants grown under LED-A showed significantly increased plant dry mass of $81.86 \%$ compared to the control group ( $<<0.05$; Fig. $2 \mathrm{~d}$ ). There was no significant difference among the groups on plant canopy width.

When the lighting was applied for $6 \mathrm{~h}$ in CLTL winter, the plants height under the LED-B treatment was significantly higher than that of the LED-A and control groups 


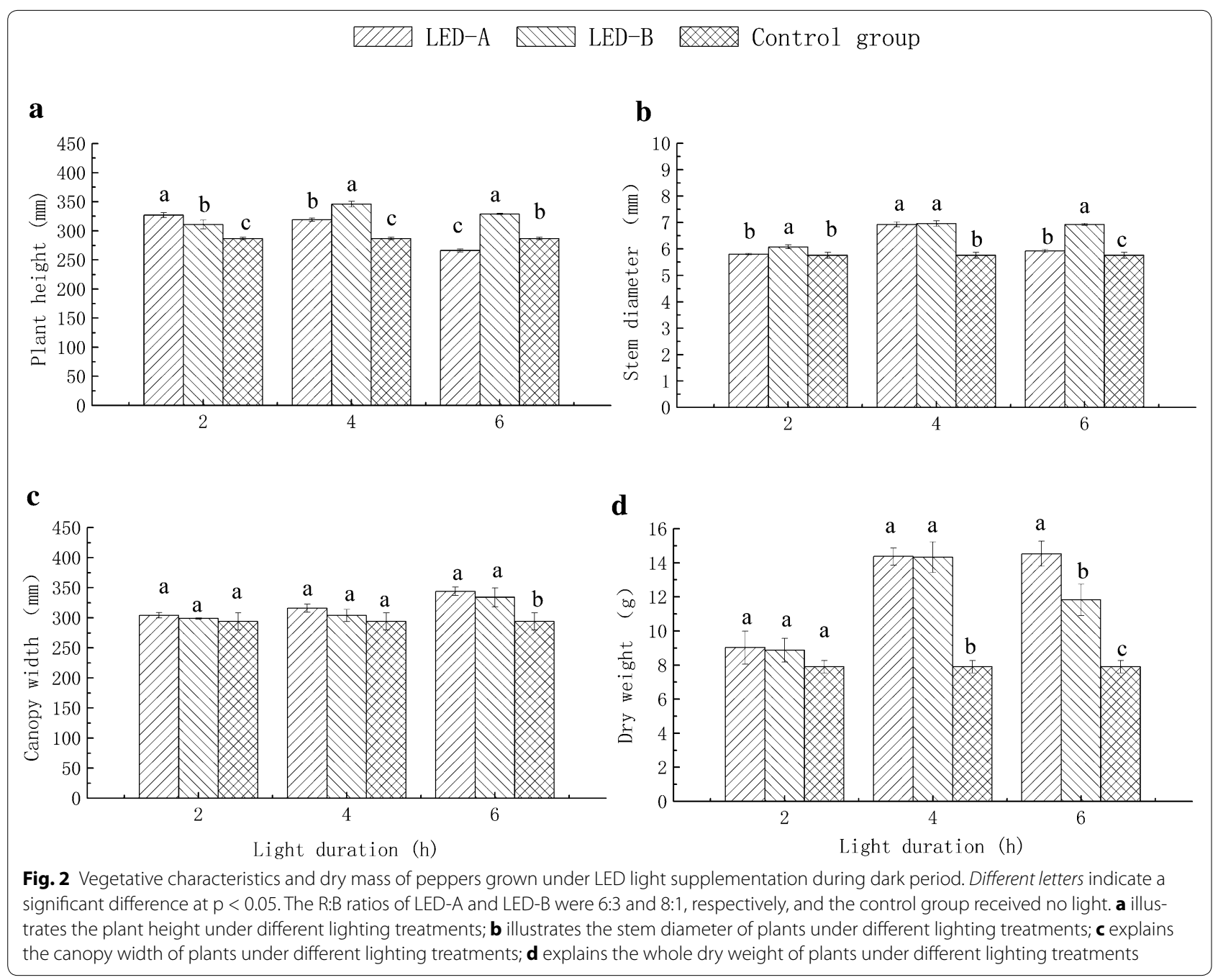

$(\mathrm{p}<0.05)$, with a $14.63 \%$ increase compared to the control (Fig. 2a). The stem diameter of plants grown under the LED-B treatment was significantly greater than that of plants under the LED-A treatment, and was increased by $20.31 \%$ compared to the control (Fig. 2b). The plant canopy width under LED-A was $17.01 \%$ greater than that of the control (Fig. 2c; p < 0.05). There was no significant difference in plant canopy width between the LED-A and LED-B groups. Plants grown under the LED-A treatment showed the largest plant dry mass, which was $83.96 \%$ greater than that of the control, which showed the lowest level of all groups; the difference among groups was statistically significant ( $\mathrm{p}<0.05$, Fig. $2 d$ ).

\section{Effects of different lighting strategies on early fruit yield and plant dry mass distribution}

The dry mass distribution ratio can reflect the effects of lighting on the dry mass distribution to all of the pepper plant organs, whereas the shoot-to-root ratio reflects the effects on the dry mass distribution of the underground parts relative to the over-ground parts. As shown in Table 3, the root growth of plants under LED-B was higher than the LED-A and the control, while the stem growth of plants grown under LED-B was significant greater than the control as well as the LED-A ( $<<0.05)$. Plants grown under LED-A1 showed the lowest leaf dry mass ratio, which was $24.32 \%$ lower than that of the control. Compared with the control, plants grown under the LED-B treatment showed no significant difference in the leaf dry mass ratio and fruit dry mass ratio, whereas lighting strategy LED-A1 appeared to be the most conducive for dry weight accumulation of fruits, with a $200.00 \%$ increase compared to that in the control groups. There was no significant difference in the shoot-to-root ratio among treatments excluded the LED-B2.

As shown in Table 4, LED-A promoted the greatest yield of plants in CLTL conditions of winter. In addition, the fruit fresh and dry weights per plant grown under LED-A were 
Table 3 Dry mass distribution ratio of pepper under different lighting strategies

\begin{tabular}{|c|c|c|c|c|c|}
\hline \multirow[t]{2}{*}{ Lighting strategy } & \multicolumn{5}{|c|}{ Dry mass distribution ratio of pepper } \\
\hline & Root & Stem & Leaf & Fruit & Shoot/Root \\
\hline LED-A1 & $0.14 \pm 0.01^{\mathrm{ab}}$ & $0.25 \pm 0.01^{\mathrm{e}}$ & $0.28 \pm 0.02^{d}$ & $0.33 \pm 0.02^{\mathrm{a}}$ & $6.42 \pm 1.07^{\mathrm{ab}}$ \\
\hline LED-B1 & $0.16 \pm 0.01^{\mathrm{a}}$ & $0.35 \pm 0.02^{b c}$ & $0.35 \pm 0.01^{b}$ & $0.14 \pm 0.02^{c}$ & $5.27 \pm 0.40^{b}$ \\
\hline LED-A2 & $0.14 \pm 0.02^{\mathrm{ab}}$ & $0.30 \pm 0.01^{d}$ & $0.30 \pm 0.01^{c}$ & $0.26 \pm 0.03^{b}$ & $6.38 \pm 0.86^{\mathrm{ab}}$ \\
\hline LED-B2 & $0.11 \pm 0.02^{b}$ & $0.39 \pm 0.01^{\mathrm{a}}$ & $0.38 \pm 0.01^{\mathrm{a}}$ & $0.12 \pm 0.01^{\mathrm{cd}}$ & $7.67 \pm 1.19^{a}$ \\
\hline LED-A3 & $0.16 \pm 0.02^{\mathrm{a}}$ & $0.35 \pm 0.01^{b c}$ & $0.37 \pm 0.01^{\mathrm{a}}$ & $0.12 \pm 0.01^{\mathrm{cd}}$ & $5.27 \pm 0.21^{b}$ \\
\hline LED-B3 & $0.15 \pm 0.02^{\mathrm{a}}$ & $0.37 \pm 0.01^{\mathrm{a}}$ & $0.38 \pm 0.01^{\mathrm{a}}$ & $0.10 \pm 0.00^{d}$ & $5.73 \pm 0.83^{b}$ \\
\hline Control group & $0.16 \pm 0.01^{\mathrm{a}}$ & $0.35 \pm 0.01^{b c}$ & $0.37 \pm 0.01^{\mathrm{a}}$ & $0.11 \pm 0.01^{\mathrm{cd}}$ & $5.13 \pm 0.21^{b}$ \\
\hline
\end{tabular}

Data are the mean \pm SD of each group. Different letters in same column indicate a significant difference at $p<0.05$

Table 4 Early fruits yield of pepper under different LED lighting strategies

\begin{tabular}{|c|c|c|c|c|}
\hline \multicolumn{2}{|c|}{ Lighting strategy } & \multirow{2}{*}{$\begin{array}{l}\begin{array}{l}\text { Average fresh } \\
\text { weight (g plant }\end{array}{ }^{-1} \text { ) } \\
32.67 \pm 2.00^{\mathrm{a}}\end{array}$} & \multirow{2}{*}{$\begin{array}{l}\begin{array}{l}\text { Average dry } \\
\text { weight (g plant }\end{array}{ }^{-1} \text { ) } \\
4.75 \pm 0.38^{\mathrm{a}}\end{array}$} & \multirow{2}{*}{$\begin{array}{l}\begin{array}{l}\text { Average } \\
\text { fruit number }\end{array} \\
9.3 \pm 0.7^{\mathrm{a}}\end{array}$} \\
\hline LED-A & LED-A1 & & & \\
\hline & LED-A2 & $26.50 \pm 1.68^{\mathrm{ab}}$ & $3.79 \pm 0.52^{b}$ & $6.0 \pm 0.7^{b}$ \\
\hline & LED-A3 & $22.98 \pm 4.44^{b c}$ & $1.05 \pm 0.15^{d}$ & $6.5 \pm 0.7^{b}$ \\
\hline \multirow[t]{3}{*}{ LED-B } & LED-B1 & $16.15 \pm 5.85^{c d}$ & $1.68 \pm 0.50^{c}$ & $6.0 \pm 0.7^{b}$ \\
\hline & LED-B2 & $14.4 \pm 7.10^{\text {de }}$ & $1.72 \pm 0.20^{c}$ & $5.6 \pm 0.7^{b}$ \\
\hline & LED-B3 & $8.3 \pm 0.4^{\mathrm{e}}$ & $0.92 \pm 0.08^{d}$ & $6.3 \pm 0.7^{b}$ \\
\hline \multicolumn{2}{|c|}{ Control group } & $8.1 \pm 1.40^{e}$ & $0.79 \pm 0.04^{d}$ & $5.7 \pm 0.7^{b}$ \\
\hline
\end{tabular}

Data are the mean \pm SD of each group. Different letters in same column indicate a significant difference at $p<0.05$

significantly higher than those of the LED-B and control groups, with increases of 238.02 and $305.06 \%$ compared to the control, respectively. Together, these results demonstrate that supplementary lighting augmented plant dry mass production (Fig. 2d), and promoted partitioning of the dry mass to the fruit (Tables 3 and 4). Moreover, LED-A supplementation could reduce the distribution of the dry mass of plants to the stems and leaves, resulting in an effective increase in fruit dry mass accumulation to ultimately increase plant yield. Specifically, plants grown under the LED-A1 strategy showed the highest fruit yield per plant, which was significantly higher than that of control group with a 303.33 and $501.27 \%$ increase in fresh weight and dry mass of fruits, respectively.

\section{Chlorophyll fluorescence characteristics under different lighting strategies during the dark period}

The Fv/Fm ratio is the potential maximum photosynthetic ability, which is steadily maintained at $0.8-0.85$ in healthy plants, and decreases in stress conditions; thus, $\mathrm{Fv} / \mathrm{Fm}$ is an importance index for studying the impact of various environmental stresses on plant photosynthesis (Björkman and Demmig 1987; Pathre and Shirke 2003). Table 5 shows that the CLTL environment in winter did not destroy the photosynthetic function of peppers plants, given that the Fv/Fm ratio remained basically stable at 0.8-0.85. Furthermore, the trends in Fv/Fm dynamics were similar among the LED-A, LED-B, and control group (Fig. 3), showing an increase trend, indicating that all of the pepper plants became increasingly stronger and healthier and that the initial light energy conversion efficiency was maintained. Peppers had the highest Fv/Fm under the LED-A1 condition (Table 5).

The parameter $\mathrm{Y}$ (II) is used to directly estimate the efficiency of the actual captured energy of the PSII photosynthetic reaction center (Bilger and Björkman 1990), reflecting the amount of excitation energy reaching the PSII reaction center (Schreiber et al. 1995). The electron transfer rate (ETR) is used to reflect the photosynthesis rate under the actual light intensity (Kramer et al. 2004). As shown in Table 5, the Y(II) and ETR values in the experimental groups were higher than those in the control group. The Y(II) and ETR values of plants under LED-A1 strategy were significantly higher than those in the control group and other treatment groups $(\mathrm{p}<0.05)$; the maximum values observed in the LED-A1 group were 113.70 and $114.34 \%$ higher than the control group, respectively. This indicated that the LED-A1 strategy is the most helpful for improving the photoreaction rate of the PSII reaction center, which in turn promotes the electron transfer ability of the PSII to ultimately increase the assimilatory power (ATP and NADPH) in PSI and improves the dry mass accumulation of peppers. 
Table 5 Effects of LED supplementation on chlorophyll fluorescence parameters of pepper

\begin{tabular}{|c|c|c|c|c|c|}
\hline Lighting strategy & $\mathrm{Y}(\mathrm{II})$ & ETR & $\mathrm{qL}$ & NPQ & $\mathrm{Fv} / \mathrm{Fm}$ \\
\hline LED-A1 & $0.312 \pm 0.090^{\mathrm{a}}$ & $11.81 \pm 3.51^{\mathrm{a}}$ & $0.321 \pm 0.130^{a}$ & $1.419 \pm 0.256^{d}$ & $0.831 \pm 0.014^{\mathrm{a}}$ \\
\hline LED-B1 & $0.259 \pm 0.065^{b}$ & $9.89 \pm 2.59^{b}$ & $0.216 \pm 0.085^{b}$ & $1.605 \pm 0.210^{\mathrm{ab}}$ & $0.820 \pm 0.013^{c d}$ \\
\hline LED-A2 & $0.201 \pm 0.066^{c}$ & $7.02 \pm 2.96^{c}$ & $0.131 \pm 0.072^{c}$ & $1.570 \pm 0.249^{b c}$ & $0.829 \pm 0.015^{\mathrm{a}}$ \\
\hline LED-B2 & $0.176 \pm 0.049^{c}$ & $7.40 \pm 1.50^{c}$ & $0.135 \pm 0.039^{c}$ & $1.700 \pm 0.187^{\mathrm{a}}$ & $0.827 \pm 0.011^{a b}$ \\
\hline LED-A3 & $0.178 \pm 0.073^{c}$ & $6.76 \pm 2.81^{c}$ & $0.126 \pm 0.073^{c}$ & $1.622 \pm 0.183^{\mathrm{ab}}$ & $0.821 \pm 0.019^{b c}$ \\
\hline LED-B3 & $0.146 \pm 0.053^{d}$ & $5.65 \pm 1.93^{d}$ & $0.104 \pm 0.047^{c}$ & $1.439 \pm 0.270^{d}$ & $0.818 \pm 0.012^{\mathrm{cd}}$ \\
\hline Control group & $0.146 \pm 0.059^{d}$ & $5.51 \pm 2.24^{d}$ & $0.103 \pm 0.063^{c}$ & $1.479 \pm 0.286^{\mathrm{cd}}$ & $0.815 \pm 0.012^{d}$ \\
\hline
\end{tabular}

Data are the mean \pm SD of each group; Different letters in same column indicate a significant difference at $p<0.05$

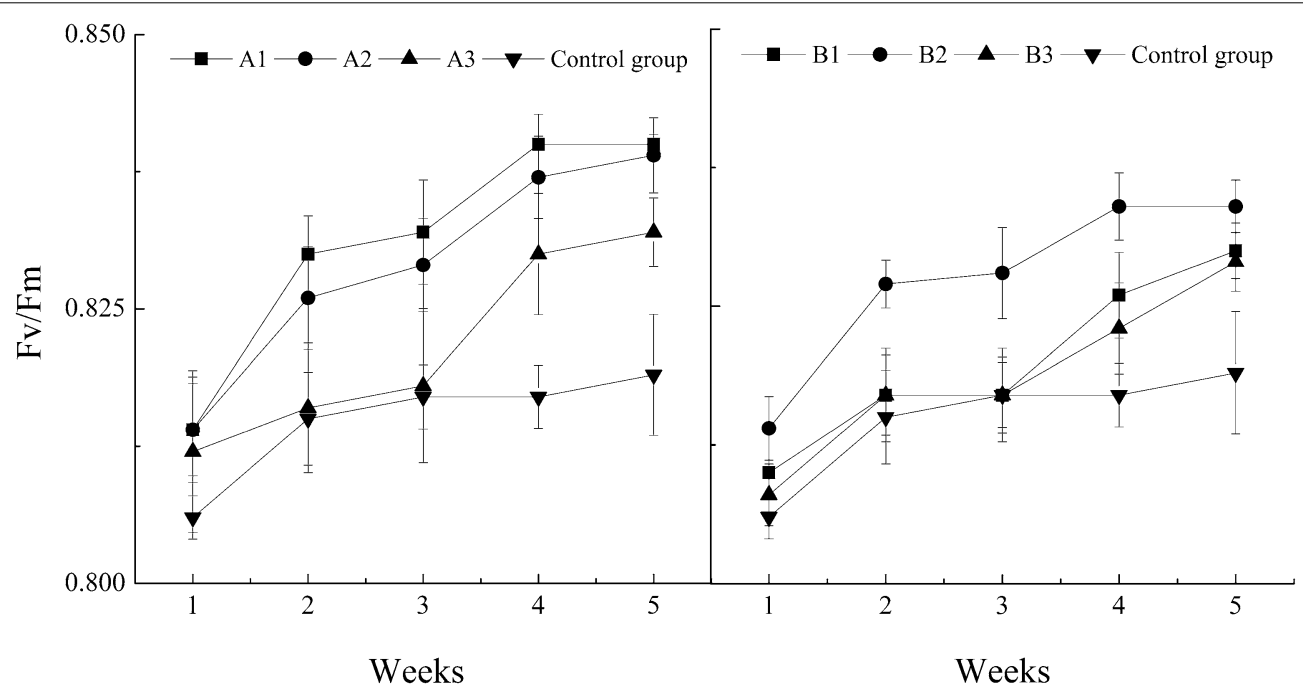

Fig. $3 \mathrm{Fv} / \mathrm{Fm}$ curve of pepper leaves for different weeks under different light supplementation strategies at night. Data are the mean \pm SD of each group

The parameter $\mathrm{qL}$ reflects the proportion of light absorbed by the antenna pigment in PSII for the photochemical reaction (Kramer et al. 2004), and NPQ is proportional to the rate constant of thermal energy dissipation, which is related to the plant self-protection mechanism of the photosynthetic apparatus in a stressful environment (Zribi et al. 2009). Plants grown under the LED-A1 strategy had the highest $\mathrm{qL}$, which was significantly higher $(\mathrm{p}<0.05)$ than that of other treatments with a $211.65 \%$ increase compared to the control. In addition, there was a significantly correlated relation among $\mathrm{qL}, \mathrm{Y}(\mathrm{II})$ and ETR $(\mathrm{p}<0.01)$, indicating that these parameters were to reflect the actual redox degree of photoelectrons in PSII. The NPQ of plants under the LED-B treatment was significantly higher than that of other groups; especially LED-B2 was the highest one with a $14.94 \%$ increase compared to the control, indicating that the light absorbed by the plant's antenna pigments was dissipated as heat to a greater extent in the LED-B light quality, and that the plants' self-protection mechanisms of the photosynthetic apparatus in PSII was strengthened. The
NPQ of plants under the LED-A1 strategy was the lowest, significant lower than the groups and with a $4.06 \%$ increase compared to the control, indicating that more light could be used for the photochemical reaction under this condition (Table 5).

\section{Effects of light quality and lighting duration on the chlorophyll fluorescence parameters in winter}

As shown in Table 6, the light source of LEDs had a significant effect on $\mathrm{Y}(\mathrm{II}), \mathrm{qL}, \mathrm{Fv} / \mathrm{Fm}$, and ETR values $(\mathrm{p}<0.01)$. The lighting duration had extreme significant influence on all chlorophyll fluorescence parameters $(\mathrm{p}<0.01)$. Light source and lighting duration had a significant impact on Fv/Fm and ETR $(\mathrm{p}<0.05)$ and a highly significant effect on $\mathrm{qL}$ and NPQ $(\mathrm{p}<0.01)$.

\section{Discussion}

China's Yangtze River Delta region is the most concentrated area of horticulture cultivation in the country, and its economic benefits directly reflect the productivity 
Table 6 Two-way ANOVA results (F-values) for effects of supplementary light source and duration on the chlorophyll fluorescence parameters of pepper plants

\begin{tabular}{lcrrrr}
\hline Source & Y(II) & QL & NPQ & Fv/Fm & ETR \\
\hline Light source & $20.128^{* *}$ & $18.393^{* *}$ & 2.274 & $10.089^{* *}$ & $7.848^{* *}$ \\
Light duration & $85.719^{* *}$ & $104.381^{* *}$ & $7.046^{* *}$ & $7.986^{* *}$ & $80.325^{* *}$ \\
Light & 1.012 & $12.104^{* *}$ & $15.821^{* *}$ & $3.138^{*}$ & $4.604^{*}$ \\
$\quad \begin{array}{l}\text { source } \times \text { Light } \\
\text { duration }\end{array}$ & & & & & \\
* and ** indicate significant difference at $\mathrm{p}<0.05$ and $\mathrm{p}<0.01$, respectively
\end{tabular}

level of horticulture cultivation of China. However, due to its geographical location and meteorological conditions, the area is subject to more than 1 month of a harsh CLTL environment in winter, with severe consequences for production in plants grown in a greenhouse without a heater. Therefore, studies focused on improving greenhouse production in winter in this region should be a priority on the basis of plant physiology combined with agricultural engineering technology theory. In this study, LED artificial supplementary lighting technology was exposed to pepper plants grown in a greenhouse under CLTL winter conditions during dark periods to detect the influences of different light supplementation strategies on the growth and development of pepper plants.

Hao and Papadopoulos (1999) found that plant dry mass production could be increased through lighting supplementation, and dry mass allocation was increased to the fruit and decreased to the stem. In this study, the total and fruits dry mass of plants with light supplementation was significantly higher than the control, however, though the stem dry mass ratio under LED-B was significant higher than the control but it was decreased under LED-A, plant height and stem diameter were higher under LED-B than under LED-A and control lighting conditions, the stem and leaf dry mass ratio of plants under the LED-B strategy were higher than those under LED-A and control conditions, indicating that red light plays an important role in promoting elongation of the plant stem and dry matter accumulation, in order to guide assimilation of the mass to the stem and leaf (Moe et al. 2002). Blue light facilitates leaf expansion and helps to assimilate products to the fruit (Chu et al. 1999; $\mathrm{Ni}$ et al. 2009). Thus, the stem dry mass ratio of plants under LED-A, in this study, was lower than the control. While, the pepper leaf width was slightly higher under LED-A than that under LED-B and the control, and the fruit dry mass ratio and yield were significantly higher under LED-A than those of LED-B plants.

The duration of supplementary lighting directly affects the photoperiod of the plant, which determines the duration of plant photosynthesis, thereby affecting carbohydrate metabolism and the absorption and transformation of nutrients (Jin et al.2014). In this study, plants under an LED-A1 and LED-B1 strategies with an 18-h photoperiod showed the largest fruit dry mass ratio as well as fruit fresh weight and dry mass per plant, followed by the LED-A2 and LED-B2 strategies with a 14-h photoperiod; the LED-A3 and LED-B3 treatments showed the lowest values with respect to productivity.

The photosynthesis ability of plant leaves is directly proportional to the $\mathrm{R} / \mathrm{B}$ ratio of LEDs (Hogewoning et al. 2010). While the results of this study showed that both light source and light duration had a significant impact on ETR (can be used to evaluate the photosynthetic rate of plant leaves), qL (the open ratio of photochemical reaction in PSII), Fv/Fm and NPQ. Therefore, in this study the R/B ratio of the LEDs is only one aspect that contributes to photosynthetic ability. In addition, the $\mathrm{Fv} /$ Fm of plants under LED-A was higher than that under LED-B when the lighting duration was the same, and was significantly increased compared to that of the control group. These results suggest that when using supplementary lighting sources with different $\mathrm{R} / \mathrm{B}$ ratios, an LED with a higher amount of blue would increase the $\mathrm{Fv} / \mathrm{Fm}$, which could improve the original capturing ability of light and enhance the health of peppers. However, the optimal R/B ratio requires further study as well as the duration of supplementary lighting.

\section{Conclusions}

The results of the present study showed several benefits of LED supplementary lighting during the dark period for pepper plants grown in greenhouse in a CLTL environment. First, LED-A is particularly beneficial for promoting the production of peppers grown in the winter in a greenhouse without a heater, whereas LED-B is helpful to increase the height and stem of plants. Second, the photosynthesis ability of plants was influenced by both light source and the lighting duration of the supplementary lighting setting. In addition, a lighting setting with a high blue-to-red light ratio is more favorable for enhancing the pepper plant's natural ability to capture light energy and can improve the photosynthetic ability of the plants as well.

\section{Abbreviations}

CLTL: continuous low temperature and poor light; h: hour; PSII: photosystem II; Y(II): the light quantum yield of PSII; ETR: electron transfer rate; qL: fraction of PSII centers that are open; NPQ: rate constant of non-photochemical quenching; Fv/Fm: maximum photochemical efficiency of PSII.

\section{Authors' contributions}

$X \mathrm{~L}$ conceived the experiments, analyzed the data and drafted the manuscript. $X L, W L, G Y H$ and ZCF performed the experiment. XCW and $Y Z$ approved the manuscript. We also thank GXS for his input during the experiment. All authors read and approved the final manuscript. 


\section{Author details}

${ }^{1}$ College of Engineering, Nanjing Agricultural University, Nanjing, Jiangsu, People's Republic of China. ${ }^{2}$ Jiangsu Province Engineering Lab for Modern Intelligent Facilities of Agriculture Technology \& Equipment, Nanjing, Jiangsu, People's Republic of China.

\section{Acknowledgements}

This study was supported by the Natural Science Foundation of China (Project No. 61273227) and the Natural Science Foundation of Jiangsu Province (Project No. BK20150686).

\section{Competing interests}

The authors declare that they have no competing interests.

Received: 7 September 2015 Accepted: 27 December 2015

Published online: 18 January 2016

\section{References}

Barta DJ, Tibbitts TW, Bula RJ, Morrow RC (1992) Evaluation of lighting-emitting diodes characteristics for a space-based plant irradiation source. Adv Space Res 12:141-149

Bilger W, Björkman O (1990) Role of the xanthophylls cycle in photoprotection elucidated by measurements of light induced absorbance changes, fluorescence and photosynthesis in leaves of Hedera canariensis. Photosynthesis Res 25:173-185

Björkman O, Demmig B (1987) Photon yield of O2 evolution and chlorophyll fluorescence characteristics at $77 \mathrm{~K}$ among vascular plants of diverse origins. Planta 170:489-504

Blom TJ, Ingratta FJ (1984) The effect of high pressure sodium lighting on the production of tomatoes, cucumbers and roses. Acta Horticulturae 148:905-914

Chen M, Tang YL (2013) Chlorophyll fluorescence characteristics of Amaranthus tricolor L. under high temperature stress. Chin J Ecol 7:1813-1818

Chu ZX, Tong Z, Feng LJ, Zhang Q, Wen XG, Song ST, Zhu XF (1999) Effect of different light quality on photosynthetic characteristics of cucumber leaves. Acta Botanica Sinica 8:867-870

Ding JJ, Yang ZC, Wang PB, Geng FZ, Gao B (2005) Influence of LED light intensity on growth and photosynthetic characteristics of non-heading Chinese cabbage. J Northwest A and F Univ (Nat.) 3:113-118

Fan ZQ, Yu X, Wang J (2008) Effect of light intensity on leave physiological activity of Brassica campestris L. Anhui Agric Sci Bull 20(26-27):39

Fang W, Jao RC (1996) Simulation of light environment with fluorescent lamps and design of a movable light mounting fixture in a growing room. Acta Horticulturae 440:181-186

Franklin KA, Whitelam GC (2007) Light-quality regulation of freezing tolerance in Arabidopsis thaliana. Nat Genet 11:1410-1413

Franklin KA, Ortiz GT, Pyott DE, Halliday KJ (2014) Interaction of light and temperature signaling. J Exp Bot 11:2859-2871

Hao XM, Papadopoulos AP (1999) Effects of supplemental lighting and cover materials on growth, photosynthesis, biomass partitioning, early yield and quality of greenhouse cucumber. Sci Horticulturae 80:1-18

Hogewoning SW, Trouwborst G, Maljaars H, Poorter H, van Leperen W, Harbinson J (2010) Blue light dose-responses of leaf photosynthesis, morphology, and chemical composition of Cucumis sativus grown under different combinations of red and blue light. J Exp Bot 11:3107-3117

Hu HW, Yu JQ (2003) Effect of low temperature and low light on the growth, development and physiological functions of tomato plants. Chin J Ecoagric 3:55-57

Janda T, Majláth I, Szalai G (2014) Interaction of temperature and light in the development of freezing tolerance in plants. J Plant Growth Regul 30:460-469
Jin ZY, WANG SS, Liu N, Gong B, Liu SQ, Shi QH (2014) Effect of different light supplement time and method on bulbing enlargement and nutritional quality of greenhouse-grown garlic. Acta Horticulturae Sinica 12:2411-2418

Kramer DM, Johnson G, Kiirats O, Edwards GE (2004) New fluorescence parameters for the determination of QA redox state and excitation energy fluxes. Photosynth Res 79:209-218

Marcelis LFM (1993a) Fruit growth and biomass allocation to the fruits in cucumber 1. Effect of fruit load and temperature. Sci Horticulturae 54:1078-1121

Marcelis LFM (1993b) Fruit growth and biomass allocation to the fruits in cucumber 2. Effect of irradiance. Sci Horticulturae 54:123-130

Moe R, Morgan L, Grindal G (2002) Growth and plant morphology of Cucumis sativus and fuchsia hybrids are influenced by light quality during the photoperiod and by temperature alternations. Acta Horticulturae 580:229-234

Nhut DT, Takamura T, Watanabe H, Tanaka M (2003) Efficiency of a novel culture system by using light-emitting diode (LED) on in vitro and subsequent growth of micro propagated banana plantlets. ISHS Acta Horticulturae 616:121-127

$\mathrm{Ni} \mathrm{JH}$, Chen XH, Chen CH, Xu Q (2009) Effects of supplemental different light qualities on growth, photosynthesis, biomass partition and early yield of greenhouse cucumber. Scientia Agricultura Sinica 7:2615-2623

Patel D, Basu M, Hayes S, Majláth I, Hetherington FM, Tschaplinski TJ, Franklin KA (2013) Temperature-dependent shade avoidance involves the receptor like kinase ERECTA. Plant J 73:980-992

Pathre UV, Shirke PA (2003) Diurnal and seasonal changes in photosynthesis and photosystem2 photochemical efficiency in prosopis juliflora leaves subjected to natural environmental stress. Photosynthetica 41:173-185

Ren ZH, Huang W, Zhang MF (2002) Effects of low temperature and poor light on some physiological parameters of tomato. J Chin Agric Univ 1:95-101

Schreiber U, Bilger W, Neubauer C (1995) Chlorophyll fluorescence as a non-invasive indicator for rapid assessment of in vivo photosynthesis. In: Schulze ED, Caldwell MM (eds) Ecophysiology of Photosynthesis. Springer, Berlin Heidelberg, pp 49-70

Shen BY, Li YN, Zhao SQ, Ding WM, Hui N, Li J (2014) Effect of dark period lighting regulation on cucumber seedling morphology and comprehensive evaluation analysis and comprehensive evaluation. Transactions of the Chinese Society of Agricultural Engineerin. 22:201-208

Wang YJ, Zhang HY, Zhang F, Xu Y, Cao WH, Kang GB (2001) Effects of low temperature and low light intensity stress on Photosynthesis in seedlings of different cucumber varieties. Acta Horticulturae Sinica 3:230-234

Wu CC (2011) The analysis and regionalization of climate for vegetable in protected cultivation in China. Chinese Master's Theses Full-text Database: S1, Agriculture Science and Technology. 2: 1-55

Xiao YX, Gao XJ, Zhou FM (2013) Effect of supplemental lighting on growth and development of Tobacco. Tianjin Agric Sci 11:85-87

Yang QC (2008) Application and prospect of Light Emitting Diode (LED) in agriculture and bio-industry. J Agric Sci Technol 6:42-47

Zoratti L, Karppinen K, Escobar AL, Häggman H, Jaakola L (2014) Light-controlled flavonoid biosynthesis in fruits. Front Plant Sci 5:1-16

Zribi L, Fatma G, Fatma R, Salwa R, Hassan N, Ne'jib RM (2009) Application of chlorophyll fluorescence for the diagnosis of salt stress in tomato "Solanumly copersicum (variety Rio Grande)". Sci Horticulturae 120:367-372 